\title{
OPSTANDING EN ONSTERFELIJKHEID IN HET NIEUWE TESTAMENT EN IN DE ANTIEKE WERELD*
}

In Nederland-hoewel waarlijk niet alleen daar-is sinds een aantal jaren een discussie gaande rondom het thema opstanding en onsterfelijkheid, soms dan ook in de zin van de keuze tussen beide: opstanding of onsterfelijkheid. Het boekje van Van der Leeuw, dat in sterke mate deze discussie op gang heeft gebracht, heeft in de titel ,onsterfelijkheid of opstanding?" weliswaar een vraagteken, maar de inhoud bewijst duidelijk genoeg dat Van der Leeuw inderdaad op een besliste keuze aandringt. Nadrukkelijk wijst hij de populaire onsterfelijksvoorstellingen, die in het hedendaagse Christendom gangbaar zijn, af. Het valt niet moeilijk, om uit geschriften als van Korff 1 ) of van Van Niftrik2) uitspraken samen te lezen die in dezelfde richting wijzen, zij het, dat Van der Leeuw de tegenstelling op enkele punten wel bijzonder scherp heeft toegespitst.

Het vorige jaar nu, in 1955, is voor de theologische faculteit te Groningen een dissertatie verdedigd, waarvan de titel reeds enigszins een program inhoudt: Het Christelijk onsterfelijkheidsgeloof.3) De schrijver kiest daarin positie tegenover hen, die het onsterfelijksgeloof afwijzen mede op grond van een onderzoek van het Nieuwe Testament. Weliswaar wijst

*Dic skrywer hiervan is hoogleraar in die N.T. vakke aan die Gemeentelijke Universiteit van Amsterdam.

J. F. W. A. Korff: Onsterfelijkheid, 1946.

2. G. C. van Niftrik: Kleine Dogmatiek, 1944.

3. P. J. van Leeuwen: Het Christelijk onsterfelijksgeloof, 1955. 
ook hij het, wat hij noemt, filosofische onsterfelijksgeloof beslist van de hand, maar, zo schrijft hij ,daarnaast doet zich het feit voor, dat wij in de Bijbel herhaaldelijk een onsterfelijksverwachting aantreffen die wezenlijk deel uitmaak van de heilsverkondiging".4) Hij acht het gewettigd om te spreken van „een legitiem bijbels onsterfelijksgeloof", 5 ) al erkent hij elders in zijn boek, dat de voorstelling van de onsterfelijke ziel, hoewel niet geheel vreemd aan het N.T., nergens een bijzondere nadruk ontvangt en al moeten wij ook volgens hem ons voor ogen houden dat het bijbelse ziels-begrip nimmer zonder lichamelijkheid wordt gedacht.6)

M.i. springen uit deze beide laatste restricties-geen nadruk, en: de ziel nooit zonder lichamelijkheid gedacht—een paar punten naar voren, die bij de problematiek rondom de verhouding van onsterfelijkheid en opstanding zeer belangrijk zijn. Want zij zien aanduidingen, dat er wel degelijk een onderscheid is en blijft tussen een verkondiging die de opstanding centraal stelt en een gedachtenwereld waarin de onsterfelijkheid in het middelpunt staat. En men doet het thema „opstanding en onsterfelijkheid" geen recht, als men het behandelt als een samenstelling van allerlei meer of minder interessante wetenswaardigheden over bepaalde eindverwachtingen, maar, goed verstaan, dringt het onherroepelijk tot een peilen van de achtergronden. Hier geldt nog steeds: „Der Eschatologe musz fast alle seine theologischen Geheimnisse verraten".7)

Kunnen dan die beide woorden gelden als tekenen voor twee gedachtenwerelden in de oudheid, opstanding voor de Christelijke, onsterfelijkheid voor de Grieks-Romeinse? En zijn zij aldus aanduiding van een scherpe tegenstelling? Het is niet zo gemakkelijk op deze vragen een duidelijk antwoord te geven, als men niet tevreden is met een voorbarige generalisering, die krampachtig de ogen sluit voor variaties en details. Misschien is het op één punt niet zo moeilijk om tot een eenstemmig oordeel te komen: opstanding is een kernwoord van het hele N.T., niet alleen in de brieven van Paulus (bijv. 1 Cor. 15:14, 17,32), die door bepaalde omstandigheden gedrongen werd om opzettelijk van de opstanding getuigenis af te leggen, maar ook in de andere geschriften van het N.T., waar de centrale betekenis van de opstanding doorlopend verondersteld wordt.

Even duidelijk is, dat de aanvallen op het Christendom vanaf de aanvang juist tegen de opstanding gericht geweest zijn. Met allerlei argumenten

4. P. J. van Leeuwen: a.w., blz. 277.

5. ib., blz. 278.

6. ib., blz. 372 .

7. P. Aithaus: Die letsten Dinge 4 1933, S. V111. 
tonen de bestrijders van het Christendom de onhoudbaarheid van het geloof in de opstanding aan. En het dunkt hun niet moeilijk op dit punt de Christenen hopeloos vast te zetten, als het maar niet zulk een onnozel troepje lichtgelovige lieden was, zoals Celsus minachtend constateert, bestaande uit wolbewerkers, schoenmakers, vollers en andere alleronbeschaafdste en allerboerste lieden.8) Ook Porphyrius vindt het beroep der Christenen op de almacht Gods niet steekhoudend, omdat deze immers in de wetten der natuur zijn grenzen heeft. Bovendien: hoe moet bij de opstanding het lichaam van een schipbreukeling weer bij elkaar gebracht worden, die door harders is opgegeten, die door vissers worden gevangen en geconsumeerd, terwijl die vissers op hun beurt weer gedood worden en door honden opgevreten, die zelf weer de buit worden van raven en gieren?9) Zo zijn de Grieken op di Areopagus niet de laatsten geweest die zich resoluut van de prediking van Paulus afwendden en gingen spotten, toen hij begon te spreken ower de opstanding der doden (Hand. 17:31, 32). Het verzet hiertegen van de zijde van de tegenstanders van het Christendom is algemeen.

Veel moeilijker zijn de vragen ten aanzien van de onsterfelijkheid. Kan het geloof daaraan kenmerkend heten voor de Grieks-Romeinse wereld? Natuurlijk moet dan allereerst, ook op dit punt gelijk op alle andere, zakelijk vastgesteld worden, dat een Grieks-Romeinse gedachtenwereld als een harmonische eenheid niet bestaat. Soms wordt elk geloof in onsterfelijkheid fel geloochend, gelijk door de oudere Plinius. Grafschriften variëren van een tere weemoed tot een wrange, bittere spot of een onverbloemde aansporing om van dit leven te halen, wat er van te halen is. De uitspraken van verschillende Romeinse schrijvers lopen wijd uiteen, soms zelfs binnen eenzelfde filosofenschool als van de Stoa.10) Ja, zelfs in de geschriften van eenzelfde wijsgeer binnen de Stoa, Seneca, vallen uitspraken, die ogenschijnlijk moeilijk met elkaar te rijmen vallen, en misschien nog het best met elkaar in overeenstemming te brengen zijn, als men veronderstelt dat hij zelf zeer sceptisch stond tegenover elk geloof aan onsterfelijkheid, maar zich soms door een behoefte om mensen in het aangezicht van de dood te bemoedigen liet verleiden tot troostwoorden, waarin hij zelf, als hij zich niet gedachteloos

8. Origenes: Contra Celsum 3.44, cf. 5.14.

9. Porphyrius: Fragm, 94, cf. 93, 35.

10. Cf. L. Friedlaender: Sittengeschichte Roms, Phaidon-Verlag, 1934, S. 1017 ff.; E. Rodhe: Psyche 4 , 1907, II S. 310 ff. 
aan een schone droom overgeeft, 11 ) niet gelooft. Zeker, de dood heeft niets schrikwekkends. Integendeel, in steeds nieuwe wendingen verheerlijkt Seneca bijna het sterven: het leven kan ons juist dierbaar worden door de weldaad, de genade van de dood.12) Hij kan de dood de schoonste uitvinding der natuur,13) de eeuwige vrede,14) de eeuwige rust noemen.15) Maar deze uitdrukkingen zeggen zonder meer nog niet zo heel veel over de vraag, wat Seneca nu eigenlijk precies van de toestand na de dood gedacht heeft. En dat met zulke uitdrukkingen toch nog wel tegelijk een scepticisme ten aansien van het leven na die dood, ja een soms besliste afwijzing daarvan gepaard kan gaan, bewijzen die plaatsen, waar Seneca zich duidelijker over deze dingen uitlaat. En dan blijkt het, dat hij soms bewust in het midden laat, wat men van de dood te verwachten heeft. Wat is de dood? Een einde? Een overgang? In beide gevallen is er niets geen reden om bang voor hem te zijn.16) Maar soms laat hij het niet bij dit alternatief en kiest hij voor de dood als einde,17) en vergelijkt hij die eeuwige vrede na de dood met de rust voor de geboorte. Dan bedoelt Seneca er kennelijk practisch een niet-zijn, een niet-existeren mee.18) Als hij dan toch nog hier en daar de mogelijkheid van de onsterfelijkheid openlaat, is dit voor hem een concessie aan de overeenstemmende meningen van mensen, welke overeenstemming gewicht in de schaal behoort te leggen, al beloven grote mannen op dit punt vaak meer dan zij bewijzen.19) Zo zet Seneca zijn eigen diepgeworteld scepticisme eigenlijk alleen daar opzij waat hij door de smart over het sterven gekwelde mensenzielen wil troosten. Tegenover verslagen zielen vindt hij het verantwoord om over het leven en de dood klanken van grotere beslistheid te laten horen dan die in zijn eigen twijfelmoedige ziel gehoord worden, als hij zijn ogen wijd open heeft en uit die schone droom ontwaakt is.20)

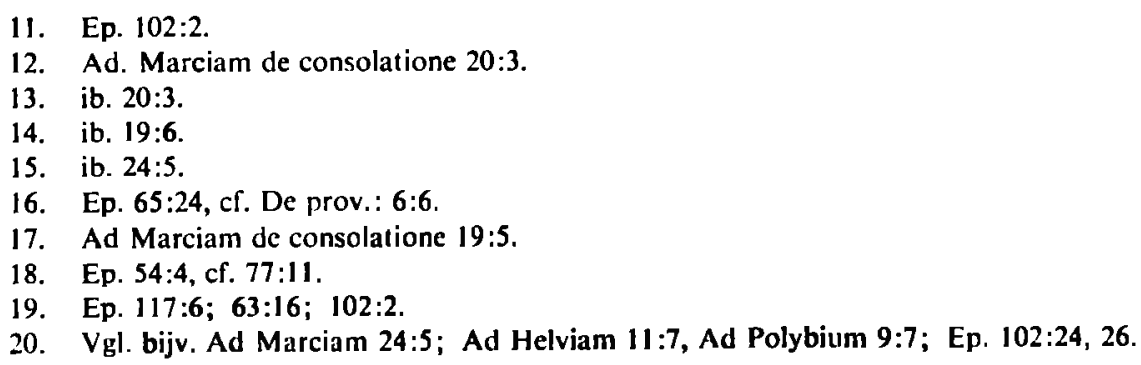


Zo is de situatie in de Stoa en in het bijzonder in de geschriften van Seneca bij uitstek geschikt om de gecompliceerdheid van de verhouding tussen de Grieks-Romeinse gedachtenwereld en het geloof in de onsterfelijkheid te laten zien. Men kan daarom zeker niet met evenveel recht zeggen dat de onsterfelijkheid kenmerkend is voor de Grieks-Romeinse gedachtenwereld als dat de opstanding het is voor die van het N.T. En toch, het is niet onzeker, waar het onsterfelijksgeloof, tot op deze dag toe, in de eerste plaats zijn oorsprong heeft. Het is bij hem, dien Rohde genoemd heeft ,der grosse Denker und Dichter, der den theologischen Gedanken der persönlichen Unsterb lichkeit mitten im Herzen der Philosophie anpflanzte." En ook ieder zal het, meen ik, Rohde toegeven, wanneer hij de invloed van Plato ook op dit punt zowel in de oudheid als daarna geweldig groot acht.21) Die invloed reikte zonder twijfel tot ver buiten de grenzen van zijn tijd en land. Als de Alexandrijnse Jood Philo herhaaldelijk getuigt van zijn geloof in de onsterfelijkheid,22) dan heeft hij ook op dit punt, gelijk op zo menig ander, de invloed van Plato ondergaan. Of als sommige Oudtestamentische Apocriefen zoals de Wijsheid van Salomo en 4 Maccabeeën dit geloof op een enkele plaats laten doorschemeren, dan is het niet onwaarschijnlijk dat ook hier een Hellenistisch Jodendom aan het woord is dat, langs welke wegen dan ook, met Platonische denkbeelden bekend geworden is.23)

Merkwaardig is ook--en dit bewijst nog eens, dat de verhoudingen ten aanzien van de onsterfelijkheid veel ingewikkelder liggen dan ten aanzien van de opstanding-dat de onsterfelijkheid van de zijde van het Christendom volstrekt niet altijd die bestrijding ontmoet heeft als de opstanding van de kant van de Grieken. Zeker, soms wordt de onsterfelijkheid der ziel nadrukkelijk afgewezen. De oudste apologeten en kerkvaders betogen herhaaldelijk met klem, dat men die gedachte niet voor Christelijk moet houden, in de woorden van Justinus Martyr: „Aanvaardt hen niet als Christenen, die zeggen dat er geen opstanding der doden is, maar dat hun zielen tegelijk met het sterven opgenomen worden".24) En meermalen wordt door hen ook duidelijk gezegd, waarom de ziel niet onsterfelijk kan zijn. Zij behoort tot de geschapen wereld en kan dus nooit het leven van nature,

21. E. Rhode: a.w. II, S. 265.

22. Spec. leg. 1:81; So. 1:127; Op. mu, 119, cf. Conf. ling. 149; Op. mu. 154

23. Sap. Sal. $3: 1,4 ; 9: 15 ; 4$ Macc. 14:5, 6; 18:23.

24. Dial. cum Tryphonc 80:4. 
in zichzelf hebben. Als zij leven heeft, heeft zij dat alleen krachtens Gods wil.25)

Zo ontbreekt de bestrijding van de onsterfelijkheid der ziel van de zijde van het Christendom allerminst. En toch heeft men ook op dit punt vaak volstrekt niet het besef gehad ,,that no Christian can possibly be a Platonist nor any Platonist a Christian".26) Zo wordt bijv. de onsterfelijkheid der ziel in een van de Apostolische Vaders, in de brief aan Diognetus, reeds met zoveel woorden verkondigd, geheel in Platonische zin: „onsterfelijk woont de ziel in een sterfelijke woning" (6:8).

Men heeft tot op heden toe vaak allerminst een tegenstelling tussen Christendom en Platonisme gezien. Integendeel, men heeft vaak het laatste voor een wegbereider van het eerste gehouden, juist op dit punt van het Platonische dualisme tussen lichaam en ziel, dat zo vanzelfsprekend uitloopt op de onsterfelijkheid der ziel. De classicus W. Nestle meent, dat men boven Plato's Gorgias het woord van Jezus zou kunnen zetten: Wat baat het een mens de gehele wereld te winnen en zijn ziel schade te doen lijden.27) Een Christelijk schrijver drukt dit een weinig anders uit, maar zegt in de grond hetzelfde, als hij schrijft, dat in het dualisme van Plato reeds een vermoeden van dit woord van Jezus aanwezig was.28) Of wanneer Rohde het gewicht van het planten van de theologische gedachte van de persoonlijke onsterfelijkheid midden in het hart der filosofie mee daarin ziet, dat Plato, „wenn er ihn so den Philosophen vertraut machte, den Theologen tiefer begr ündet zurückgab,"29) komt blijkbaar bij hem geen ogenblik de gedachte op, dat de theoloog dit geschenk zou kunnen weigeren.

Zo liggen de moeilijkheden ten aanzien van de onsterfelijkheid met alleen daarin, dat het niet zo eenvoudig te zeggen is, in hoeverre deze kenmerkend is voor de Grieks-Romeinse gedachtenwereld, maar ook hierin, dat niet zo dadelijk vast te stellen is, in hoeverre het geloof in de onsterfelijkheid tegenover dat in de opstanding staat. Bovengenoemde uitlatingen zouden doen vermoeden, dat men volstrekt niet van een tegenstelling tussen deze beide kan spreken. En tog bestaat deze m.i. wel degelijk, tenminste zodra het geloof in de onsterfelijkheid, gelijk bij Plato, gegrond is in een scherp

25. Dial. 5, 6; Tatianus: Oratio ad Graecos 13:1; Irenaeus: Adr. haer. 1I: 34.

26. W. H. V. Reade: The Christian Challenge to Philosophy, 1951, p. 70.

27. W. Nestle: Griechische Weltanschauung in ihrer Bedeutung für die Gegenwart, 1946, S. 241.

28. H. W. Rüssel: Antike Welt und Christentum, 1944, S. $146 \mathrm{f}$.

29. E. Rhode: a.w. II, S. 265. 
anthropologisch dualisme en het de toekomst van de enkele mens centraal stelt. Zeker, het is wel begrijpelijk, dat men ook bij het lezen van het N.T. meende hier en daar duidelijk aan Plato herinnerd te worden. Hebben woorden als Mc. 8:36, Mt. 10:28, Rom. 7:24 niet een Platonische klank? Herinnert 2 Cor. 5:1 niet aan Sap. Sal. 9:15, dat op zijn beurt een sprekende overeenkomst vertoont, zelfs tot in de bewoording, met Phaedo $81 \mathrm{C}$ ? Tegenover dat woord van Jezus tot zijn leerlingen: ,Weest niet bevreesd voor hen, die wel het lichaam doden, maar die ziel niet kunnen doden" (Mt. 10:28), kan men moeilijk volhouden, gelijk Van der Leeuw dat herhaaldelijk in zijn boekje beweert, dat het bijbels is om te zeggen, dat de ziel sterft.30) Inderdaad, en toch, juist dit woord van Jezus kan, vanuit zijn eigen achtergrond gelezen, reeds een duidelijk vermoeden geven van het diepgaande verschil met de Platonische gedachte van de onsterfelijkheid der ziel. In de eerste plaats valt het op, dat op die parallelle plaats bij Lucas het woord ziel eenvoudig ontbreekt (Luc. 12:4, 5, cf. 2 Clem, 5:4). Juist die afwijkende lezing doet vermoeden, dat het woord ,ziel" in dit verband volstrekt geen nadruk heeft, en ook dit woord van Jezus niet gehoord moet worden vanuit een Platonische verhecrlijking van een in zichzelf onsterfelijke ziel. De bedoeling is allereerst, aan de leerlingen voor te houden dat mensen, als zij hen doden, daarna niets meer kunnen doen, maar dat de leerlingen wel moeten bedenken: dan komen zij te staan voor God, die beide, lichaam en ziel, kan verderven in de hel. En in dat vervolg ligt de tweede, veel belangrijker, aanwijzing, dat de klank der woorden er niet toe mag leiden om hier de Platonische leer der onsterfelijkheid der ziel te lezen. Mt. 10:28b bewijst, dat niet het ogenblik van de dood op zichzelf het beslissende is, maar dat wat God doet bij het oordeel, bij de opstanding der doden, met de ganse mens, lichaam én ziel. De beslissende scheidingslijn loopt niet tussen de twee delen van de mens, waarvan het een, ,het lichaam", weliswaar aan het verderf en de vergankelijkheid word prijsgegeven bij het sterven, maar het andere, ,de ziel", in zichzelf, krachtens zijn eigen aard, zijn verwantschap met het goddelijke, zeker mag zijn van de onsterflijkheid. Over de toekomst van de ganse mens wordt werkelijk beslist door de vrijmachtige wil van de souvereine God, die met al dat menselijke kan doen wat $\mathrm{Hij}$ wil.

Dan is er geen sprake van, dat de dood op zichzelf reeds de bevrijding zou zijn. Waar de onsterfelijkheid der ziel verkondigd wordt, moet wel

30. G. van der Leeuw: Onsterfelijkheid en Opstanding 3, 1938, blz. 31, 36. 
de nadruk vallen op het ogenblik van het sterven zelf. Waar een scherp dualisme tussen lichaam en ziel aanvaard wordt en het lichaam veracht, de ziel verheerlijkt wordt, moet wel het ogenblik van het sterven het belangrijkst geacht worden, het ogenblik, waarin de scheiding van lichaam en ziel plaats heeft.31) En dan valt er toch niets te klagen, als men in de dood nu eindelijk eens bereikt wat men altijd in het leven reeds begeerde te verkrijgen. De ware wijsgeren immers maken reeds in dit leven een studie van het sterven; dan spreekt het toch vanzelf dat het denkbeeld van dood zijn hun niet het minst ter wereld schrik aanjaagt. Zij zullen toch niet droevig zijn, als zij in de dood datgene verkrijgen, wat zij hun ganse leven lang nagestreefd hebben.32) Het spreekt vanzelf, dat de dood als de verlossing gezien wordt, als het lichaam beschouwd wordt als de kerker der ziel, waaruit deze laatste bij de dood bevrijd wordt33), als een lijkkist, een lijkurn, een - grafteken.34)

Hoe verschillend hier in wezen over de dood gedacht wordt, kan misschien scherp worden gezegd in aansluiting bij een uitdrukking van Paulus over de dood, zoals het door twee classici geschied is, door W. Nestle in zijn opstel over „Die Haupteinwände des antiken Denkens gegen das Chriskutuur" 35 ): „Der Tod ist für ihn (de antieke mens) ein notwendiger, gottgewollter Naturvorgang, für den Christen dagegen der Sünde Sold," door Friedlaender in zijn "Sittengeschichte Roms", als hij spreekt over de Orphisch-Pythagorese leer van de zielsverhuizing: „Hier war also nicht der Tod der Sünde Sold, sondern das Leben"36) Inderdaad, voor Paulus is de dood het loon, dat de zonde geeft (Rom. 6:23), door hem wordt de dood allerminst als een natuurgebeuren aanvaard, voor hem is de dood die verschrikkelijke macht, die eens door de zonde in de wereld is binnengedrongen. Sinsdien heerst de dood als koning over het mensengeslacht en hij zou blijven heersen, als er geen sprake was van het werk des heils dat God in Christus begonnen is en dat Hij ten einde toe zal voortsetten (Rom. 5:12, 15, 17; Phil. 1:6). En als dit ganse heilsgebeuren tot een einde gekomen zal zijn, zal de dood verzwolgen zijn in de overwinning, dan zal ook de dood, de laatste vijand, overwonnen worden (1 Cor. 15:54, 26). Van die defini-

31. Bijv. Phaedo 67 D; Seneca: de Providentia 6:9; Epictetus: Diss. III: 10:14.

32. Phaedo $67 \mathrm{E}, 68 \mathrm{~A}$.

33. Phaedo $67 \mathrm{D}$.

34. Philo: Migr. Abr. 16; Leg. All. I: 108, cf. Gig. 15, Agr. 25.

35. W. Nestle: Griechische Studien, 1948, S. 653.

36. L. Friedlaender: a.w., S. 1021. 
tieve overwinning spreekt Paulus in het hoofdstuk waarin hij tegenover een Griekse gemeente de opstanding van Christus en daarmee de opstanding der doden verkondigt. De opstanding hoort dus thuis in die ganse heilsgeschiedenis, die in zijn wezenlijke bedoeling aan het licht gekomen is, toen God in die volheid des tijds zijn Zoon heeft uitgezonden (Gal. 4:4), die verloopt langs de lijn van de verschijning van Christus op aarde, zijn dood, zijn opstanding, zijn hemelvaart, zijn wederkomst en tegelijk met deze laatste de opstanding der doden en het laatste oordeel. De opstanding maakt deel uit van dat heilsgebeuren, dat gemarkeerd wordt door de tijden en gelegenheden, die God in zijn souvereine vrijmacht heeft vastgesteld, waarover de Vader de beschikking aan zich gehouden heeft (1 Thess. 5:1, Hand. 1:7), niet door de keerpunten in het afzonderlijke mensenleven, daarom ook niet door de dood van de enkele mens. Integendeel, de toekomst van de mens wordt geheel bepaald door de toekomst van die heilsgeschiedenis. Nergens wordt dan ook in het N.T. gezegd, dat de opstanding van de mens onmiddelijk na zijn dood plaats heeft, maar de opstanding der doden is éen enkele machtige acte in de geweldige heilsorde van God.

Daaruit volgt, logisch gedacht, eigenlijk ook de noodzakelijkheid van een tussentoestand. Deze blijkt ook wel enkele malen in het N.T. verondersteld te worden (Luc. 16:22 vv.; 23:43; 2 Cor. 5:1 vv.; Phil. 1:23). Maar het is merkwaardig, dat juist aan die tussentoestand zo weinig aandacht besteed wordt, zodat wij eigenlijk nauwelijks te weten komen, wat men zich daarbij gedacht heeft. Juist echter vanuit die volle aandacht voor de keerpunten der heilsgeschiedenis is dit volkomen begrijpelijk. Dan kan immers het centrum van de belangstelling nooit liggen in het levens- en stervensgebeuren van de afzonderlijke mens, dan kan bij het sterven nooit het beslissende plaats hebben, dan kan die losmaking van de ziel uit het lichaam, waarin de Phaedo de bevrijding ziet, slechts iets voorlopigs zijn, waarop nog volgen moet die wezenlijk belangrijke opstanding der doden, waarbij aan het licht zal komen wat God zal doen met de ganse mens, lichaam en ziel beide. De opstanding maakt deel uit van een heilshistorie en hoort daarom in cen geheel ander kader thuis dan de onsterfelijkheid der ziel in Platonische zin.

Het berust dan ook geheel op een misverstand om te menen dat de aandacht in het Christendom allereerst geconcentreerd zou zijn op het lot van de enkele mens na de dood. En het gaat niet aan, om de tegenstelling tussen Grieken en Christenen hierin te zien, dat de eersten steeds de wereld en de natuur als geheel in het oog hielden, terwijl de laatsten hun gehele belangstelling op de mens zouden concentreren en daarom aan de Christenen 
een anthropocentrische wereldbeschouwing toe te dichten.37) Hoe kan men dat volhouden, als men in de evenageliën leest van dat verloop der heilsgeschiedenis, van dat rijk Gods, dat in Jezus Christus reeds gekomen is (Mt. 12:28; Luc. 10:18; 17:20 v.), dat zijn voleinding, ook in de kosmos tegemoetgaat, of als ook Paulus de kosmische afmetingen van Gods heilswerk in Christus nadrukkelijk verkondigt (Col. 1:15, 17) en voor de ganse schepping, die nu nog in al haar delen zucht en in barensnood is, de volkomen verlossing verwacht (Rom. 8:19 vv.).Waar zo de ganse aandacht gericht is op de grote daden van Gods heil, ook van de verlossing van de kosmos, kan toch moeilijk een anthropocentrische wereldbeschouwing de overhand krijgen. Zeker, het oudste Christendom denkt anders over de kosmos dan de Grieken. Een zakelijk belangrijke tegenstelling wordt aangeduid in die woorden van Stauffer: „Dem Griechentum ist die Geschichte nur eine Erscheinung innerhalb des Kosmos. Dem Ur-Christentum dagegen ist der Kosmos nur eine Erscheinung innerhalb der Geschichte. Der Grieche lauscht auf die ewige Harmonie der Sphären. Die Männer des Neuen Testaments horchen auf den Schritt der Allgeschichte"38). Hemel en aardc, mens en kosmos zijn in één machtige heilsorde van God opgenomen. En daartoe behoort ook de opstanding der doden, die men dus grondig misverstaat, als men er een teken van een anthropocentrische wereldbeschouwing in ziet.39)

Als zo de uitgangspunten van het geloof in de onsterflijkheid der ziel en dat in de opstanding der doden verschillend zijn, ligt het voor de hand, dat dit verschil op allerlei punten aan de dag zal komen. Dat blijkt ook daar, waar op het eerstc gezicht misschicn een zekere overecnkomst schijnt te bestaan. Men dient zich dan cchter door zulk een oppervlakkige ovcreenstemming in woorden niet te laten misleiden en niet al te haastig parallellen te construeren daar, waar er door de dieper liggende verschillen eigenlijk volstrekt geen aanleiding toe bestaat.

Het woord ,,onsterfelijkheid", athanasia, komt ook in het Nicuwe Testament voor. Veelzeggend is dan alvast, dat het heel weinig voorkomt, slechts tweemaal en dat men het woord ,onsterfelijk", athanatos, nergens in het N.T. vindt. En één van die twee malen wordt van de onstcrfelijkheid gezegd, dat zij alleen aan God tockomt (1 Tim. 6:16). De andere maal komt het woord voor in het hoofdstuk over de opstanding (1 Cor. 15:53 vv.).

37. Zo bijv. W. Nestle: Gricchische Studien, 1948, S. 639 f., 655.

38. E. Stauffer: Die Theologie des N. Testaments, 1945, S. 60.

39. Cf. Cullmann: Le retour du Christ, 1945; p. 20; Chrustus und die Zeit, 1946, S. 206. 
Daar klinkt het misschien aanvankelijk Grieks, te meer als men in het voorafgaande gedeelte gelezen heeft: vlees en bloed kunnen het Koninkrijk Gods niet beërven (1 Kor. 15:50). Men heeft dan ook dikwijls hieruit menen te mogen opmaken, dat Paulus hier niet alleen opzettelijk tegenover die Griekse gemeente van Corinthe Griekse uitdrukkingen gebruikt-wat inderdaad aannemelijk mag heten en waarschijnlijk op meerdere plaatsen in deze brief gebeurt, maar op zichzelf niets zegt-doch daarmee ook blijk zou geven „griechische Empfinden" te delen.40) Dit is m.i. een onjuiste gevolgtrekking. Immers uit het verband is het duidelijk, dat de onsterfelijkheid, de onvergankelijkheid in 1 Cor. 15:53 v. betrekking heeft op het opstandingslichaam, dat een gave van God is, dus niet op iets, dat de mens van nature, in zichzelf heeft en dat na de dood zijn verwantschap met het goddelijke bewijst door een voortbestaan in onsterfelijkheid, maar op iets, dat behoort tot de ondoorgrondelijke wonderen van de heilsgeschiedenis van God, die bij de opstanding der doden het nieuwe opstandingslichaam schept. Dat is de onvergankelijkheid, die dit vergankelijke moet aandoen, de onsterfelijkheid, die dit sterfelijke moet aandoen. En in dat vers, ,vlees en bloed kunnen het Koninkrijk Gods niet beërven", is niet slechts ,, het Koninkrijk Gods" een term, die een centraal begrip van de Joods-Christelijke heilsgeschiedenis aanduidt, maar is ook ,vlees en bloed" een typisch JoodsChristelijke uitdrukking, die meer omvat dan men vanuit „griechisches Empfinden" geneigd zou zijn daaruit te horen. „Vlees en bloed” zou men kunnen verstaan als een aanduiding van het verachtelijke lichaam, die kerker waaruit de ziel verlost moet worden. Maar waar hij elders in het N.T. gebruikt wordt, is kennelijk iets anders bedoeld: dat, wat van de mens is, uit de mens is, bij het terrein van de mens behoort tegenover wat van God is, wat God doet (Mt. 16:17; Gal. 1:1, 15, 16; Eph. 6:12). En dat dit geheel in overeenstemming met de Joodse opvatting van deze term, die zeer vaak bij de rabbijnen voorkomt, gedacht is, bewijst bijv. de beschrijving van het sterven van Jochanan ben Zakkai, een van de beroemdste schriftgeleerden uit de tijd van de apostelen. Als zijn leerlingen en vrienden hem kort voor zijn sterven komen bezocken en hij begint te wenen, vragen zij hem, waarom hij weent. En hij antwoordt: als men mij zou brengen voor een koning van vlees en bloed, die heden hier is en morgen in het graf ligt, zou ik al wenen. Hoeveel te meer reden is daartoe, nu ik voor de Koning der koningen in het oordeel zal moeten verschijnen.41) Zo omvat ook bij

40. Zo bijv. Joh. Weiss: Der erst Korintherbrief, 1925, S. 345.

41. Berakoth 28 b. 
Paulus die uitdrukking ,vlees en bloed" veel meer dan alleen het vergankelijke lichaam tegenover de onsterfelijke ziel. Het heeft betrekking op al het menselijke. Paulus wil zeggen: het toekomstige leven in de opstanding is niet een regelrechte voortzetting van dit aardse, menselijke leven. Het is anders, nieuw door de herschepping van God. Alleen de herscheppende daad van God verleent de onvergankelijkheid.

En hoe weinig dit alles Platonisch gedacht is, blijkt wel, als Paulus in dit zelfde hoofdstuk antwoord geeft op de vraag, hoe de doden worden opgewekt (1 Cor. 15:35 vv.). Scherp wordt de tegenstelling tussen het nu en het dan geformuleerd: Er wordt gezaaid in vergankelijkheid, en opgewekt in onvergankelijkheid; er wordt gezaaid in oneer, en opgewekt in heerlijkheid; er wordt gezaaid in zwakheid en opgewekt in kracht. Er wordt een natuurlijk lichaam gezaaid, en een geestelijk lichaam opgewekt (1 Cor. 15:42, 44). Vooral dit laatste klinkt, vanuit de Platonische leer va $n$ de onsterfelijkheid der ziel gehoord, zeer vreemd. Zoals eerder in deze brief de ongeestelijke mens, de psuchikos anthropos, gesteld wordt tegenover de geestelijke, de pneumatikos (1 Cor. 2:14 v.), zo hier het natuurlijke lichaam, het soma psuchikon, tegenover het geestelijke, het pneumatikon. In het ,psuchikon" wordt blijkbaar geen ongenblik meer de lofzang van Plato gehoord op de ziel, de psuche, als zeer gelijk aan het goddelijke, onsterfelijke,42) maar dat soma psuchikon heeft het nodig om door God tot iets geheel anders herschapen te worden, voordat het opstandingslichaam, het soma pneumatikon, ontstaat. En in die term soma pneumatikon ligt niet opgesloten, dat wel een ander decl van de mens, het pneuma, vanzelfsprekend in de samestelling van dat opstandingslichaam wordt opgenomen, dat toch iets in de mens van nature onsterfelijk zou zijn, want het adjectief pneumatikos duidt in dit geval niet op een samenhang met een menselijk pneuma, dat iedere mens eigen zou zijn, maar herinnert aan dat pneuma, dat aan een mens daar God geschonken wordt en dat daarmee behoort tot de gaven van de eindtijd. Als Paulus in deze zelfde brief de ontucht veroordeelt en uitroept: of weet gij niet, dat uw lichaam een tempel is van de Heilige Geest, die in u woont (1 Cor. 6:19), dan doet hij daarmee niet een beroep op een kostbare, onvergankelijke geest, die in iedere mens onbesmet moet blijven, maar dan spreekt hij een Christelijke gemeente aan op het bezit van die Heilige Geest, die geen mens van nature eigen is, maar die daarom in de leden der gemeente van Christus verondersteld mag worden, omdat zij die van God ontvangen hebben. Het is de Geest, die God nu reeds als eschatologische heilsgave meedeelt, die daarom eersteling (Rom.

$\overline{42 \text { Phaedo } 80}$ B. 
8:23), onderpand (2 Cor. 1:22; 5:5; Eph. 1:14) genoemd mag worden. In dat geestelijke lichaam ligt dus niet de continuiteit met iets goddelijks in iedere mens opgesloten, maar het betekent, dat op de $n u$ reeds geschonken eersteling dan de volle oogst gaat volgen, dat dan de erfenis wordt uitgekeerd aan hen die $n u$ reeds in die Geest daarvan een onderpand bezitten. Ook hier staat alles in het raam niet van het verloop van het lot van de enkele mens allereerst, maar van het heilswerk, dat God in Christus is aangevangen en dat $\mathrm{Hij}$ tot het einde toe zal voltooien.

J. N. SEVENSTER. 